Pacific Journal of Mathematics

LENGTH OF PERIOD SIMPLE CONTINUED FRACTION 


\section{LENGTH OF PERIOD OF SIMPLE CONTINUED FRACTION EXPANSION OF $\sqrt{d}$}

\section{DEAN R. HICKERSON}

In this article, the length, $p(d)$, of the period of the simple continued fraction (s.c.f.) for $\sqrt{ } \bar{d}$ is discussed, where $d$ is a positive integer, not a perfect square. In particular, it is shown that

$$
p(d)<d^{1 / 2+\log 2 / \log \log d+o\left(\log \log \log d /(\log \log d)^{2}\right)} .
$$

In addition, some properties of the complete quotients of the s.c.f. expansion of $\sqrt{ } \bar{d}$ are developed.

It is well known that the s.c.f. expansion for $\sqrt{d}$ is periodic if $d$ is a positive integer, not a perfect square. Throughout this paper, $p(d)$ will denote the length of this period. It is shown in [2] (page $294)$, that $p(d)<2 d$. Computer calculation of $p(d)$ originally suggested that $p(d) \leqq 2[\sqrt{d}]$. This was shown to be false for $d=1726$, for which $p(d)=88$ and $2[\sqrt{d}]=82$. Further calculation revealed 3 more counterexamples for $d \leqq 3000$. They were $p(2011)=94$ while $2[\sqrt{2011}]=88, p(2566)=102$ while $2[\sqrt{2566}]=100$, and $p(2671)=104$ while $2[\sqrt{2671}]=102$.

This suggests as a conjecture that

$$
p(d)=O\left(d^{1 / 2}\right) \quad \text { and } \quad p(d) \neq o\left(d^{1 / 2}\right) .
$$

It follows from the corollary to Theorem 2 that

$$
p(d)=O\left(d^{1 / 2+\varepsilon}\right)
$$

or more precisely, that

$$
p(d)<d^{1 / 2+\log 2 / \log \log d+O\left(\log \log \log d /(\log \log d)^{2}\right)} .
$$

We will need the following results which are given in or follow from $\S \S 7.1-7.4$ and 7.7 of [1].

(1) Any periodic s.c.f. is a quadratic irrational number, and conversely.

(2) The s.c.f. expansion of the real quadratic irrational number $(a+\sqrt{b}) / c$ is purely periodic if and only if $(a+\sqrt{b}) / c>1$ and $-1<(a-\sqrt{b}) / c<0$.

(3) Any quadratic irrational number $\xi_{0}$ may be put in the form $\xi_{0}=\left(m_{0}+\sqrt{\bar{d}}\right) / q_{0}$, where $d, m_{0}$, and $q_{0}$ are integers, $q_{0} \neq 0, d \geqq 1, d$ is not a perfect square, and $q_{0} \mid\left(d-m_{0}^{2}\right)$. We may then define infinite 
sequences $m_{i}, q_{i}, a_{\imath}$, and $\xi_{i}$ by the equations $\xi_{i}=\left(m_{i}+\sqrt{\bar{d}}\right) / q_{i}, a_{i}=$ $\left[\xi_{i}\right], m_{i+1}=a_{i} q_{i}-m_{i}$, and $q_{i+1}=\left(d-m_{i+1}^{2}\right) q_{i}$. Then, for $i \geqq 0, m_{i}, q_{i}$, and $a_{i}$ are integers, $q_{i} \neq 0$, and $q_{i} \mid\left(d-m_{i}^{2}\right)$. Also, for $i \geqq 1, a_{i}$ and $\xi_{i}$ are positive.

(4) In the notation of (3) above, we have for $i \geqq 0, \xi_{i}=$ $\left\langle a_{i}, a_{i+1}, a_{i+2}, \cdots\right\rangle$. In particular, $\xi_{0}=\left\langle a_{0}, a_{1}, a_{2}, \cdots\right\rangle$.

(5) There is a positive integer $N$ such that, if $i>N$, then $q_{i}>0$.

(6) There exist nonnegative integers $j$ and $k$ such that $j<k$, $m_{\jmath}=m_{k}$, and $q_{\jmath}=q_{k}$. We may choose $j$ to be the smallest integer such that for some $k>j, m_{j}=m_{k}$ and $q_{j}=q_{k}$. We may then choose $k$ to be the smallest integer such that $j<k, m_{j}=m_{k}$, and $q_{j}=q_{k}$. Then, if $t$ is a nonnegative integer, then $m_{\jmath+t}=m_{k+t}, q_{j+t}=q_{k+t}$, $a_{j+t}=a_{k+t}$, and $\xi_{j+t}=\xi_{k+t}$. Therefore, if $i<j$, then

$$
\xi_{i}=\left\langle a_{i}, a_{i+1}, \cdots, a_{j-1}, \overline{a_{j}, \cdots, a_{k-1}}\right\rangle,
$$

while if $i \geqq j$, then $\xi_{i}=\left\langle\overline{a_{i^{\prime}}, a_{i^{\prime}+1}, \cdots, a_{k-2}, a_{k-1}, a_{j}, a_{j+1}, \cdots, a_{i^{\prime}-1}}\right\rangle$, where $i^{\prime}$ is the integer such that $j \leqq i^{\prime} \leqq k-1$ and $i \equiv i^{\prime}(\bmod (k-j))$. In particular, $\xi_{0}=\left\langle a_{0}, a_{1}, \cdots, a_{j-1}, \overline{a_{\jmath}, \cdots, a_{k-1}}\right\rangle$.

(7) If $\xi_{0}=\sqrt{\bar{d}}$ then we may take $m_{0}=0$ and $q_{0}=1$ in (3). In (6), we have $j=1$ and $k=r+1$ for some positive integer $r$. Then $\xi_{0}=\left\langle a_{0}, \overline{a_{1}, \cdots, a_{r}}\right\rangle$ and, for $i \geqq 1, \xi_{i}=\left\langle\overline{a_{i^{\prime}}, \cdots, a_{r}, a_{1}, \cdots, a_{i^{\prime}-1}}\right\rangle$, where $i^{\prime}$ is such that $1 \leqq i^{\prime} \leqq r$ and $i \equiv i^{\prime}(\bmod r)$.

(8) In (7), if $t \geqq 0$ then $m_{1+t}=m_{r+1+t}, q_{1+t}=q_{r+1+t}, a_{1+t}=a_{r+1+t}$, and $\xi_{1+t}=\xi_{r+1+t}$. It follows from this that if $i \geqq 1$ and $s \geqq 0$, then $m_{i+r s}=m_{i}, q_{i+r s}=q_{i}, a_{i+r s}=a_{i}$, and $\xi_{i+r s}=\xi_{i}$.

Throughout this paper it will be assumed that $d$ is a positive integer, not a perfect square. The period $r$ of the s.c.f. expansion of $\sqrt{\bar{d}}$ will be denoted by $p(d)$.

2. Preliminary results. In this section, $m_{i}, q_{i}, a_{i}$, and $\xi_{i}$ will refer to the sequences defined in (3)-(8) above, with $\xi_{0}=\sqrt{d}, m_{0}=$ 0 , and $q_{0}=1$.

LEMma 1 . If $i \geqq 0$, then $q_{i}>0$.

Proof. From (5), there is an $N$ such that, if $i>N$, then $q_{i}>0$. Suppose $i \geqq 1$. Then there is an integer $s$ such that $i+r s>N$. By (8), $q_{i}=q_{i+r s}$. But since $i+r s>N, q_{i+r s}>0$. Therefore, $q_{i}>0$. That is, if $i \geqq 1$, we are done. Since $q_{0}=1$, this result holds for $i=0$ also, so the proof is complete.

Theorem 1. If $i \geqq 1$, then $0<m_{i}<\sqrt{\bar{d}}$ and $\sqrt{d}-m_{i}<q_{i}<$ $\sqrt{d}+m_{i}$. 
Proof. From (7), if $i \geqq 1$, then $\xi_{i}=\left\langle\overline{\left\langle a_{i^{\prime}}, \cdots, a_{r}, a_{1}, \cdots, a_{i^{\prime}-1}\right.}\right\rangle$ so the s.c.f. for $\xi_{i}$ is purely periodic. But $\xi_{i}=\left(m_{i}+\sqrt{\bar{d}}\right) / q_{i}$, so from (2), $\quad\left(m_{i}+\sqrt{\bar{d}}\right) / q_{i}>1$ and $-1<\left(m_{i}-\sqrt{\bar{d}}\right) / q_{i}<0$. Since, from Lemma $1, q_{i}>0$, we obtain $m_{i}+\sqrt{\bar{d}}>q_{i}$ and $-q_{i}<m_{i}-\sqrt{\bar{d}}<0$. This yields $m_{i}<\sqrt{\bar{d}}$ and $\sqrt{\bar{d}}-m_{i}<q_{i}<\sqrt{\bar{d}}+m_{i}$.

Thus $-m_{i}<m_{i}$ and $m_{i}>0$, so the proof is complete.

For given $d$, let $T=T(d)$ be the set of ordered pairs $(m, q)$ which satisfy $m<\sqrt{\bar{d}}, \sqrt{\bar{d}}-m<q<\sqrt{\bar{d}}+m$, and $q \mid\left(d-m^{2}\right)$. That is, $T=\left\{(m, q)|m<\sqrt{\bar{d}}, \sqrt{\bar{d}}-m<q<\sqrt{d}+m, q|\left(d-m^{2}\right)\right\}$. Let $g(d)=c(T)$, the cardinality of $T$.

From (6) and (7) of Section 1 , if $1 \leqq i<l \leqq r$ then $\left(m_{i}, q_{i}\right) \neq$ $\left(m_{l}, q_{l}\right)$. Therefore, the set $U=\left\{\left(m_{i}, q_{i}\right) \mid 1 \leqq i \leqq r\right\}$ has exactly $r$ elements. By Theorem $1, U \subset T$ so $r=c(U) \leqq c(T)=g(d)$. Since $r=p(d)$, we obtain

LEMMA 2. $p(d) \leqq g(d)$.

3. An upper bound on $g(d)$.

THEOREM 2. $g(d)<d^{1 / 2+\log 2 / \log \log d+O\left(\log \log \log d /(\log \log d)^{2}\right)}$.

Proof.

$g(d)$

$=c(T)=c\left(\left\{(m, q)|0<m<\sqrt{\bar{d}}, \sqrt{\bar{d}}-m<q<\sqrt{\bar{d}}+m, q|\left(d-m^{2}\right)\right\}\right)$

$=\sum_{m=1}^{[\sqrt{d}]} c\left(\left\{q|\sqrt{\bar{d}}-m<q<\sqrt{\bar{d}}+m, q| d-m^{2}\right\}\right) \leqq \sum_{m=1}^{[\sqrt{d}]} \tau\left(d-m^{2}\right)$,

where $\tau(n)$ denotes the number of divisors of $n$.

It is shown in [3] that

$$
\log \tau(N)<\frac{\log 2 \log N}{\log \log N}+O\left(\frac{\log N \log \log \log N}{(\log \log N)^{2}}\right) .
$$

It follows that

$$
\tau(N)<N^{\log 2 / \log \log N+O\left(\log \log \log N /(\log \log N)^{2}\right)} .
$$

Therefore, for $m=1,2, \cdots,[\sqrt{\bar{d}}]$,

$$
\tau\left(d-m^{2}\right)<d^{\log 2 / \log \log d+O\left(\log \log \log d\left((\log \log d)^{2}\right)\right.},
$$

and the theorem follows by summing this expression over the $[\sqrt{\bar{d}}]<d^{1 / 2}$ values of $m$.

CoROLLARY. $\quad p(d)<d^{1 / 2+\log 2 / \log \log d+o\left(\log \log \log d /(\log \log d)^{2}\right)}$.

Proof. This follows immediately from Lemma 2 and Theorem 2. 
4. A lower bound on the order of $g(d)$. Theorem 2 shows that $g(d)=O\left(d^{1 / 2+\varepsilon}\right)$ for any $\varepsilon>0$. It will follow from Theorem 3 that $g(d) \neq o\left(d^{1 / 2}\right)$. Thus, Theorem 2 is almost best possible. This, however, is not necessarily true of its corollary.

THEOREM 3. There exist infinitely many positive integers $d$ for which $g(d)>\sqrt{d}$.

Proof. Let $n$ be an arbitrary positive integer. Let

$$
S=\{(m, q) \mid q-n \leqq m, n+1-q \leqq m, m \leqq n\} .
$$

Then, for $n^{2}+1 \leqq d \leqq n^{2}+2 n, T(d)=\{(m, q) \mid(m, q) \in S$ and $d \equiv$ $\left.m^{2}(\bmod q)\right\}$. Given $(m, q) \in S$, let $f(m, q)$ denote the number of integers $d$ for which $n^{2}+1 \leqq d \leqq n^{2}+2 n$ and $d \equiv m^{2}(\bmod q)$. Then $\sum_{d=n^{2}+1}^{n^{2}+2 n} g(d)=$ $\sum_{(m, q) \in S} f(m, q)$. However, it is easily seen that if $(m, q) \in S$, then $f(m, q) \geqq[2 n / q]$. Also, note that $S=\{(m, q) \mid 1 \leqq q \leqq n, n+1-q \leqq$ $m \leqq n\} \cup\{(m, q) \mid n+1 \leqq q \leqq 2 n, q-n \leqq m \leqq n\}$. If $1 \leqq q \leqq n$, then $[2 n / q]>2 n / q-1$. If $n+1 \leqq q \leqq 2 n$, then $[2 n / q]=1$. Therefore,

$$
\begin{aligned}
\sum_{d=n^{2}+1}^{n^{2}+2 n} g(d)= & \sum_{\langle m, q) \in S} f(m, q) \geqq \sum_{(m, q) \equiv S}\left[\frac{2 n}{q}\right]=\sum_{\substack{1 \leq q \leq n \\
n+1-q \leqq m \leqq n}}\left[\frac{2 n}{q}\right]+\sum_{\substack{n+1 \leq q \leq 2 n \\
q-n \leqq m \leqq n}}\left[\frac{2 n}{q}\right] \\
= & \sum_{q=1}^{n} q\left[\frac{2 n}{q}\right]+\sum_{q=n+1}^{2 n}(2 n+1-q)\left[\frac{2 n}{q}\right]>\sum_{q=1}^{n} q\left(\frac{2 n}{q}-1\right) \\
& +\sum_{q=n+1}^{2 n}(2 n+1-q)=2 n^{2} .
\end{aligned}
$$

It follows from this inequality that at least one of the $2 n$ numbers $g(d)$ with $n^{2}+1 \leqq d \leqq n^{2}+2 n$ must be greater than $\left(2 n^{2} / 2 n\right)=n$. Since $n=[\sqrt{\bar{d}}]$ for any such $d$, there is a $d$ such that $n=[\sqrt{\bar{d}}]$ and $g(d)>\sqrt{d}$. Since this is true for any positive $n$, the theorem follows.

\section{REFERENCES}

1. Ivan Niven and Herbert Zuckerman, An Introduction to the Theory of Numbers, 2nd ed., John Wiley and Sons, Inc., New York, 1966.

2. Waclaw Sierpinski, Elementary Theory of Numbers, Monografie Matematyczne, Poland, 1964.

3. Srinivasa Ramanujan, Collected Papers, 2nd ed., Chelsea Publishing Company, New York, 1962.

Received April 28, 1972.

University of CALifornia, Davis 


\section{PACIFIC JOURNAL OF MATHEMATICS}

\section{EDITORS}

D. Gilbarg and J. Milgram

Stanford University

Stanford, California 94305

\author{
R. A. Beaumont \\ University of Washington \\ Seattle, Washington 98105
}

J. DuGUNDJI

Department of Mathematics

University of Southern California

Los Angeles, California 90007

Richard ARENS

University of California

Los Angeles, California 90024

\section{ASSOCIATE EDITORS}
E. F. BECKENBACH
B. H. NeumanN
F. WOLF
K. YosHIDA

\section{SUPPORTING INSTITUTIONS}

UNIVERSITY OF BRITISH COLUMBIA

CALIFORNIA INSTITUTE OF TECHNOLOGY

UNIVERSITY OF CALIFORNIA

MONTANA STATE UNIVERSITY

UNIVERSITY OF NEVADA

NEW MEXICO STATE UNIVERSITY

OREGON STATE UNIVERSITY

UNIVERSITY OF OREGON

OSAKA UNIVERSITY

\author{
UNIVERSITY OF SOUTHERN CALIFORNIA \\ STANFORD UNIVERSITY \\ UNIVERSITY OF TOKYO \\ UNIVERSITY OF UTAH \\ WASHINGTON STATE UNIVERSITY \\ UNIVERSITY OF WASHINGTON
* * * *
AMERICAN MATHEMATICAL SOCIETY \\ NAVAL WEAPONS CENTER
}

The Supporting Institutions listed above contribute to the cost of publication of this Journal, but they are not owners or publishers and have no responsibility for its content or policies.

Mathematical papers intended for publication in the Pacific Journal of Mathematics should be in typed form or offset-reproduced, (not dittoed), double spaced with large margins. Underline Greek letters in red, German in green, and script in blue. The first paragraph or two must be capable of being used separately as a synopsis of the entire paper. The editorial "we" must not be used in the synopsis, and items of the bibliography should not be cited there unless absolutely necessary, in which case they must be identified by author and Journal, rather than by item number. Manuscripts, in duplicate if possible, may be sent to any one of the four editors. Please classify according to the scheme of Math. Rev. Index to Vol. 39. All other communications to the editors should be addressed to the managing editor, Richard Arens, University of California, Los Angeles, California, 90024.

50 reprints are provided free for each article; additional copies may be obtained at cost in multiples of 50 .

The Pacific Journal of Mathematics is issued monthly as of January 1966. Regular subscription rate: $\$ 48.00$ a year (6 Vols., 12 issues). Special rate: $\$ 24.00$ a year to individual members of supporting institutions.

Subscriptions, orders for back numbers, and changes of address should be sent to Pacific Journal of Mathematics, 103 Highland Boulevard, Berkeley, California, 94708.

PUBLISHED BY PACIFIC JOURNAL OF MATHEMATICS, A NON-PROFIT CORPORATION

Printed at Kokusai Bunken Insatsusha (International Academic Printing Co., Ltd.), 270, 3-chome Totsuka-cho, Shinjuku-ku, Tokyo 160, Japan. 


\section{Pacific Journal of Mathematics}

\section{Vol. 46, No. 2 December, 1973}

Christopher Allday, Rational Whitehead products and a spectral sequence of

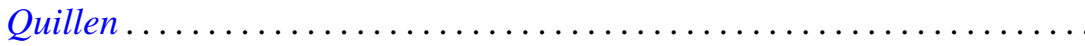

James Edward Arnold, Jr., Attaching Hurewicz fibrations with fiber

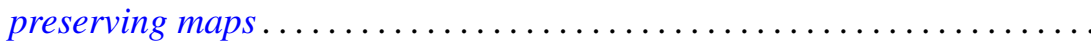

Catherine Bandle and Moshe Marcus, Radial averaging transformations with various metrics.................................

David Wilmot Barnette, A proof of the lower bound conjecture for convex

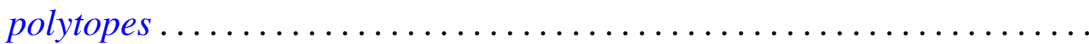

Louis Harvey Blake, Simple extensions of measures and the preservation of

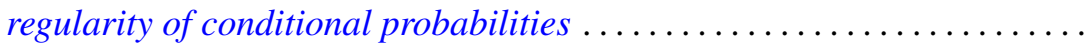

James W. Cannon, New proofs of Bing's approximation theorems for

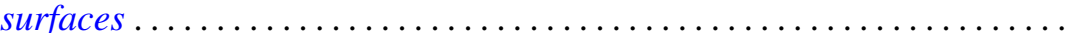

C. D. Feustel and Robert John Gregorac, On realizing HNN groups in

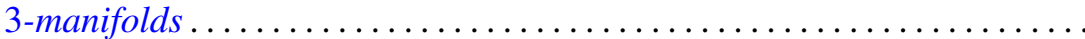

Theodore William Gamelin, Iversen's theorem and fiber algebras . . . . . . . . 389

Daniel H. Gottlieb, The total space of universal fibrations . . . . . . . . . . . .

Yoshimitsu Hasegawa, Integrability theorems for power series expansions of

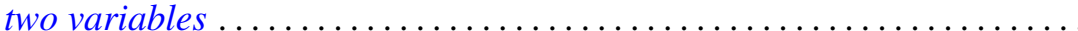

Dean Robert Hickerson, Length of period simple continued fraction expansion of $\sqrt{ } d$

Herbert Meyer Kamowitz, The spectra of endomorphisms of the disc algebra.

Dong S. Kim, Boundedly holomorphic convex domains

Daniel Ralph Lewis, Integral operators on $\mathscr{L}_{p}$-spaces ...

John Eldon Mack, Fields of topological spaces . . . . . . . . .

V. B. Moscatelli, On a problem of completion in bornology

Ellen Elizabeth Reed, Proximity convergence structures. .

Ronald C. Rosier, Dual spaces of certain vector sequence spaces .

Robert A. Rubin, Absolutely torsion-free rings

Leo Sario and Cecilia Wang, Radial quasiharmonic functions . .

James Henry Schmerl, Peano models with many generic classes .

H. J. Schmidt, The $\mathscr{F}$-depth of an $\mathscr{F}$-projector ............

Edward Silverman, Strong quasi-convexity. . . . . . . . . . . . . . . . . 549

Barry Simon, Uniform crossnorms ....................... 555

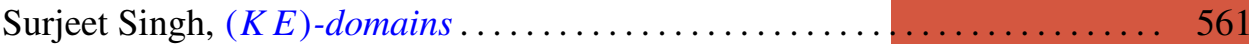

Ted Joe Suffridge, Starlike and convex maps in Banach spaces . . . . . . . . 575

Milton Don Ulmer, $C$-embedded $\Sigma$-spaces . . . . . . . . . . . . . . . . 591

Wolmer Vasconcelos, Conductor, projectivity and injectivity . . . . . . . . . 603 